\title{
Wild flower resources and insect honeydew are potential food items for Elasmus flabellatus
}

\author{
Maria Villa $^{1}$ - Sónia A. P. Santos ${ }^{1,2} \cdot$ António Mexia $^{3} \cdot$ Albino Bento $^{1}$. \\ José Alberto Pereira ${ }^{1}$
}

Accepted: 13 April 2017 / Published online: 8 May 2017

(C) INRA and Springer-Verlag France 2017

\begin{abstract}
Adult parasitoids need non-host food such as nectar or honeydew for survival and reproduction. In a conservation biological control strategy, the knowledge about non-host feeding of parasitoid species is a key factor to successfully increase their action. The nutritional behavior of Elasmus flabellatus (Fonscolombe) (Hymenoptera: Eulophidae), a major parasitoid of the olive moth, Prays oleae (Bernard) (Lepidoptera: Praydidae), is completely unknown. Survival experiments were performed on two secondary olive pest honeydews and eight common flowering plant species in order to analyze their suitability as potential food sources for E. flabellatus females. Abdomen and gut dissections were carried out to verify the pollen consumption and the egg production. Floral architecture and insect morphology were described. Cox's proportional hazard regression models were used to analyze the differences between parasitoid survivals. Honeydews secreted by Saissetia oleae (Olivier) (Hemiptera: Coccidae) and Euphyllura olivina (Costa) (Hemiptera: Psyllidae) resulted in the best performance followed by the flowers of Malva sylvestris L. (Malvaceae), Daucus carota L. (Apiaceae), and the Cichorioideae Tolpis barbata (L.) and Andryala integrifolia $\mathrm{L}$. Theoretical flower resources accessibility were assessed and related with the survival results.
\end{abstract}

José Alberto Pereira

jpereira@ipb.pt

1 Mountain Research Centre (CIMO), School of Agriculture, Polytechnic Institute of Bragança, Campus de Santa Apolónia, 5300-253 Bragança, Portugal

2 Present address: Barreiro School of Technology, Polytechnic Institute of Setúbal, Rua Américo da Silva Marinho,

2839-001 Lavradio, Portugal

3 School of Agriculture, University of Lisbon, Tapada da Ajuda, 1349-017 Lisbon, Portugal
E. flabellatus females did not consume pollen and did not produce eggs, suggesting that the species is synovigenic and requires additional foods for egg production. In sustainable pest control programs, this novel knowledge is a promising opportunity for improving suitable food resources of E. flabellatus in the field.

Keywords Nutritional ecology · Survival analysis · Cox proportional hazard model $\cdot$ Parasitoids $\cdot$ Prays oleae . Olive orchard

\section{Introduction}

Insect feeding is determined by several aspects such as availability, detectability, accessibility, and nutritional suitability of foods (Wäckers 2005). Adult parasitoid wasps need energy for maintenance, locomotion, and reproduction that is provided by non-host foods (Jervis et al. 2008). Several studies have been conducted to determine the influence of non-host resources (such as nectar, insect honeydews, and sugar solutions) on various parasitoid species. Different traits related to survival and reproduction were evaluated under laboratory and field conditions (e.g., Balzan and Wäckers 2013; Lavandero et al. 2006; Wäckers et al. 2008). In all these studies, parasitoids fed on sugary liquids. Pollen feeding by parasitoids has been studied less frequently than sugar feeding (Lundgren 2009 and references therein), and according to Jervis et al. (2008), only few groups feed on pollen (e.g., Mutillidae, Scoliidae, and some Bombyliidae). However, Patt et al. (1997) found that when crawling on the disc flowers, the Eulophidae Edovum puttleri Grissell and Pediobius foveolatus Crawford accumulated pollen on their bodies and they fed on that pollen. In other cases, parasitoids such as Trichogramma brassicae Bezdenko (Trichogrammatidae) 
benefited from pollen feeding, which increased its longevity and fecundity when fed on corn pollen (Zhang et al. 2004). Gut dissection can be used to analyze pollen consumption by insects, although few studies have been performed with parasitoid wasps (Jervis et al. 1993; Lundgren 2009).

The olive tree (Olea europaea L.) is among the oldest and most widespread crops in the Mediterranean region. Nowadays, it is cultivated in several regions of the world with climatic conditions that allow its establishment. The olive moth Prays oleae (Bernard) (Lepidoptera: Praydidae) is one of the most important pests in the olive grove agroecosystem. It has three generations a year, the phyllophagous (feeding on leaves), the anthophagous (feeding on flowers), and the carpophagous generation (feeding on fruit). This pest is parasitized by several hymenopteran species (Villa et al. 2016b); however, the information about the type of food resources exploited by them is scarce.

Species of the genus Elasmus Westwood occur in all the zoogeographical regions. Elasmus flabellatus (Fonscolombe) (Hymenoptera: Eulophidae) is an ectophagous and gregarious parasitoid, which attacks larvae and pupae of Lepidoptera order (e.g., Gelechiidae, Tortricidae, Noctuidae, Yponomeutidae, Heliozelidae, Plutellidae, Psychidae, and Pyralidae families) and larvae of Hymenoptera (e.g., Cephidae, Bethylidae, Braconidae, and Ichneumonidae families) (Yefremova and Strakhova 2010 and references therein). This is an idiobiont parasitoid, i.e., females stop the development of $P$. oleae last instar larva, lay their eggs, and develop outside of it (Bento et al. 2007). To our knowledge, there is no information about the type of ovigeny of this species. It acts as a facultative hyperparasitoid of other $P$. oleae parasitoids, and the levels of parasitism on this pest were found to vary from $10 \%$ for the phyllophagous generation (Bento et al. 2007 and reference therein) to $15.2 \%$ for the anthophagous generation (Villa et al. 2016b). Despite its hyperparasitoid behavior and parasitism rates, in some conditions, E. flabellatus can be considered an important $P$. oleae biocontrol agent. For instance, Villa et al. (2016b) found that in olive groves with herbicide application, after an extremely dry year and extraordinary low pest levels, E. flabellatus reached around the half of the overall parasitism with $10 \%$ of parasitism levels.

Usually, E. flabellatus attacks the phyllophagous and the anthophagous generations but not the carpophagous (e.g., Bento et al. 2007 and references therein). Increasing numbers of $E$. flabellatus in the agroecosystem might lead to higher parasitism of $P$. oleae larvae from the phyllophagous and the anthophagous generations and consequently to the diminution of the carpophagous generation and, more importantly, to the reduction of fruit damage. However, from the end of the anthophagous generation (at the end of the spring) to the beginning of the phyllophagous generation (at the end of the winter of the next year), E. flabellatus needs to survive. The adult feeding of $E$. flabellatus emerging from larva of the anthophagous generation is therefore crucial to its success and additional studies are needed in order to elucidate which food resources could contribute to enhance E. flabellatus in the olive grove during that period.

Moreover, honeydews produced by some olive tree secondary pests, such as the black scale Saissetia oleae (Olivier) (Hemiptera: Coccidae) and the olive psyllid Euphyllura olivina (Costa) (Hemiptera: Psyllidae), are mainly present during the anthophagous generation (Pereira 2004; Tzanakakis 2003 and references therein) and could have a final positive effect by nourishing parasitoids and improving their performance.

In this context, this work aims at (1) studying the survival of $E$. flabellatus females fed on honeydews secreted by $S$. oleae and E. olivina and eight spontaneous plant species: the Apiaceae Daucus carota L., the Asteraceae Anthemis arvensis L. and Coleostephus myconis (L.) Rchb.f. (subfamily Asteroideae), Andryala integrifolia L. and Tolpis barbata (L.) (subfamily Cichorioideae), the Boraginaceae Echium plantagineum L., the Hypericaceae Hypericum perforatum L., and the Malvaceae Malva sylvestris L., (2) analyzing the parasitoid accessibility to flower resources and the pollen consumption, and (3) determining its type of ovigeny.

\section{Materials and methods}

\subsection{Parasitoids}

E. flabellatus adults were obtained from parasitized olive moth larvae of the anthophagous generation collected in olive orchards from the Trás-os-Montes region (northeastern Portugal) at the end of the spring of 2013. In the laboratory, P. oleae larvae were transferred individually into tubes $(1.7 \mathrm{~cm}$ in diameter and $12 \mathrm{~cm}$ length), closed with Parafilm ${ }^{\circledR}$, and placed in a climate chamber at $21 \pm 2{ }^{\circ} \mathrm{C}, 70 \pm 5 \% \mathrm{RH}$, and a photoperiod of $16: 8 \mathrm{~h}(\mathrm{~L} / \mathrm{D})$ until the emergence of E. flabellatus adults used in experiments described in Sections 2.3 and 2.5.

\subsection{Selected foods}

Selected plants were A. arvensis, A. integrifolia, C. myconis, $D$. carota, E. plantagineum, $H$. perforatum, $M$. sylvestris, and T. barbata flowering at the end of the spring, simultaneously with the flight period of $E$. flabellatus that emerged from the anthophagous generation of $P$. oleae and common in several agroecosystems. The plant selection was based on (1) the existence of records for flowering specimens in the Trás-osMontes region (northeastern Portugal) in Flora-on (2015), which systematizes the geographical and ecological information of the Portuguese flora and is coordinated by the Botanical Society of Portugal, (2) their occurrence in olive 
groves during the period of study (Villa, personal observation), and (3) their abundance (enough to perform the experiments and potentially feed insects in the field). Flowers were collected in the campus of the Polytechnic Institute of Bragança (in order to minimize the period between flower collection and experiment assemblage) between 9:00 and 10:00 AM, and only flowers without aphid infestation or damages were chosen. Small drops (of about $1-2 \mu$ l of volume) of honeydews produced by $S$. oleae and E. olivina were collected overnight by placing a Parafilm ${ }^{\circledR}$ strip $\left(4 \mathrm{~cm}^{2}\right)$ under infested leaves of olive trees grown in a climatic chamber $\left[24 \pm 2{ }^{\circ} \mathrm{C}\right.$, $70 \pm 5 \% \mathrm{RH}$, and a photoperiod of 16:8 h (L/D)]. Strips with more than ten honeydew drops were used in the experiments in order to guarantee that $E$. flabellatus fed ad libitum.

\subsection{Survival experiments}

Newly emerged $(<24 \mathrm{~h})$ adult females of E. flabellatus were transferred into cages $(2.7 \mathrm{~cm}$ in diameter and $12 \mathrm{~cm}$ length) and provided with water and one of the food sources. The different treatments were carried out simultaneously, all the individuals emerged during a period of 10 days, and all the plants were flowering during the period of the experiment. Between 18 and 34 females were tested: A. arvensis-20, A. integrifolia18, C. myconis-24, T. barbata-22, E. plantagineum26, H. perforatum-22, M. sylvestris-27, D. carota32, S. oleae honeydew-31, and E. olivina honeydew25. A negative control (water) and a positive control (honey solution $10 \%, w / v$ ) were assembled (26 and 34 females, respectively). To ensure the repeatability of the experiment, a similar floral area was provided by treatment: two inflorescences of $A$. arvensis, three of A. integrifolia, one of C. myconis, three of T. barbata, two flowers of $E$. plantagineum, three of $H$. perforatum, one of $M$. sylvestris, and five umbellets of $D$. carota. The cut stems of the flowers were submerged in water in $1.5-\mathrm{ml}$ microcentrifuge tubes and closed with Parafilm ${ }^{\circledR}$. This procedure is considered adequate since previous studies did not find differences between observed lifespans with cut and non-cut flowers (Wade and Wratten 2007). In the negative and positive control treatments, water and honey $10 \%$ were provided by filling $1.5-\mathrm{ml}$ microcentrifuge tubes with a strip of filter paper and closed with Parafilm ${ }^{\circledR}$. The microcentrifuge tube was fixed inside the cage with a piece of adhesive putty. Food items were replaced three times a week, according to the durability of the flowers. Cages for survival analysis were kept in a climate chamber at $21 \pm 2{ }^{\circ} \mathrm{C}, 70 \pm 5 \% \mathrm{RH}$, and a photoperiod of $16: 8 \mathrm{~h}$ (L/D), and daily mortality was recorded until all insects were dead (Fig. 1).

\subsection{Theoretical flower resource accessibility}

Flower resource (pollen and nectar) accessibility was analyzed by determining the compatibility between flower architecture and the insect morphology. For that, the following parameters were measured in 20 specimens of each plant species: (1) in compound flowers (all Asteraceae and D. carota) the inflorescence opening (as the largest diameter of the inflorescence), (2) in open flowers $(H$. perforatum and D. carota) the flower opening (as the largest diameter of the flower), (3) in tubular flowers (E. plantagineum and disc flowers in the Asteroideae A. arvensis and C. myconis) the corolla opening (as the diameter of the narrowest part of the tube) and the depth of the flower (from the most proximal point of the corolla to the location of the nectar), and (4) in ligulate flowers (in the Cichorioideade T. barbata and A. integrifolia) the corolla length (from the most proximal point of the corolla to the location of the nectar). A caliper rule was used for structures larger than $5 \mathrm{~mm}$. Leica Application Suite X version 3.8 software (Leica Microsystems, Germany) connected to a stereomicroscope was used to measure structures smaller than $5 \mathrm{~mm}$. The head and thorax widths of 20 E. flabellatus females were measured.

\subsection{Pollen consumption and ovigeny}

Ten newly emerged $(<24 \mathrm{~h})$ adult females of E. flabellatus were transferred into cages $(2.7 \mathrm{~cm}$ in diameter and $12 \mathrm{~cm}$ length) and provided with water and one of the treatments. After 3 days, the parasitoids were frozen and then the pollen consumption and egg load were analyzed. In the case of the flower treatments, each parasitoid was washed in $96 \%$ alcohol to eliminate the external pollen. The abdomen was removed from the body and opened with the help of the scalpel, needles, and fine forceps using a stereomicroscope. In all the specimens, the abdominal content was released onto a glass slide. After that, two drops of glycerin jelly/water (1:1) were added, and a coverslip $(22 \times 22 \mathrm{~mm})$ was applied. To prevent pollen contamination between the samples, the scalpel, needles, and forceps were washed after each dissection. The consumption of pollen grains was evaluated using an optical microscope.

\subsection{Data analysis}

Firstly, 18 observations from each treatment were randomly selected using the sample function in R (R core team 2014) in order to ensure the balance of the sample size between treatments. Lifespan means and standard errors were calculated. Survival curves were represented for each treatment with Kaplan-Meier estimates using the Surv and survfit functions from the "survival" package (Therneau 2014). Death hazard 
Fig. 1 Olive grove in Trás-osMontes, northeastern Portugal (a); larvae of Elasmus flabellatus feeding on a Prays oleae larva (b); setting up of the survival experiments (c)

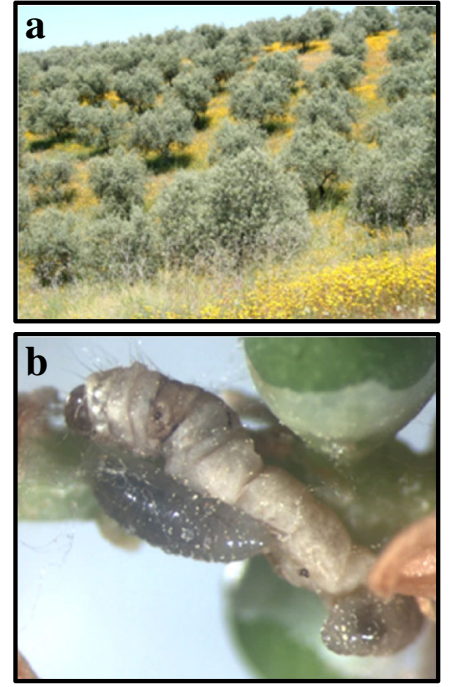

differences between treatments were checked using Cox's proportional hazard regression model (Cox PHM) (Eq. (1))

$h(t, x)=h_{0}(t) \exp \left(\sum_{i=1}^{p} \beta_{i} x_{i}\right)$

where $h(t, x)$ is the hazard function, $t$ is the time, $x \in\left\{c_{0}\right.$, $\left.c_{1}, \ldots, c_{k-1}\right\}$ represent the different treatments, $h_{0}(t)$ is the baseline, $\exp \left(\beta_{i} x_{i}\right)$ is the death hazard ratio for each treatment, and $\beta$ is the slope (Cox and Oakes 2001). This is a semiparametric model that estimates the death hazard ratio between two treatments, with the advantage of indicating the dimension of the hazard ratio variation between two treatments. A death hazard ratio of 1 indicates that no differences exist among two treatments. A death hazard ratio of $<1$ indicates lower death risk for the comparison group. A death hazard ratio of $>1$ means higher death risk for the comparison group.

The Cox PHM was estimated through likelihood ratio test and using coxph function of the survival package (Therneau 2014) and with "food treatment" as explanatory variable. Efron's partial likelihood was used to estimate $\exp \left(\beta_{i}\right)$ of the Cox PHM. The proportional hazard assumption of the Cox PHM was assessed by testing the no correlation between the Schoenfeld's residuals and the survival time using the cox.zph function of the same package and plotting the smoothed Schoenfeld's residuals against the different levels of the categorical variable. The Martingale residuals were plotted against the different levels of "food resources" to detect potential nonlinearity of the model. The occurrence of influential observations was evaluated by estimating changes in the regression coefficients upon deleting each observation in turn and diving by the standard errors using type $=$ dfbetas in residuals function in R (Fox and Weisberg 2011). An observation was considered influential if dfbetas $>1$ (Bollen and Jackman 1990).

\section{Results and discussion}

Food resources analyzed in this work are spatially and temporally coincident with $E$. flabellatus adults emerging from larvae of the anthophagous generation of $P$. oleae at the end of the spring (Flora-on 2015; Pereira 2004; Tzanakakis 2003). This synchrony enables parasitoids feeding.

Figure 2 represents the survival curves obtained by Kaplan-Meier estimates for E. flabellatus females fed on different resources. The best survival was reached with honey followed by both honeydews and the flowers of M. sylvestris, D. carota, T. barbata, and A. integrifolia.

In the Cox PHM fitted using "food resource" the proportional hazard assumption was accepted and nonlinearity was not detected. No influential observations were detected (all dfbetas $<1$ ).

The Cox PHM showed that female death hazards were significantly different among diet treatments $\left(\chi^{2}=331\right.$, $d f=11, p<0.001)$. The highest lifespan for females was observed on the honey solution (58.33 \pm 4.34 days) (Fig. 3 ). The Cox PHM showed that honey reduced the risk of death when compared with $E$. olivina $(69.60 \%$ reduction, $p=0.011)$ and $S$. oleae honeydews $(88.10 \%$ reduction, $p<0.001)$ and with all the flowers and the negative control ( $>99 \%$ reduction, $p<0.001$ ). These results suggest that honey contains components that can benefit $E$. flabellatus females. Higher quality and quantity of sugars and other minor components could be responsible for these results.

Food nutritional suitability depends on its composition and the ability of the insect to absorb, metabolize, and assimilate or store the food components (Wäckers 2005). Hemipteran honeydews contain oligosaccharides that are thought to be involved in osmoregulation functions (Byrne et al. 2003), but also in evasive strategies to avoid honeydew consumption by parasitoids and non-mutualistic predators (Wäckers 2005 and references therein). Sugar composition of honeydews 

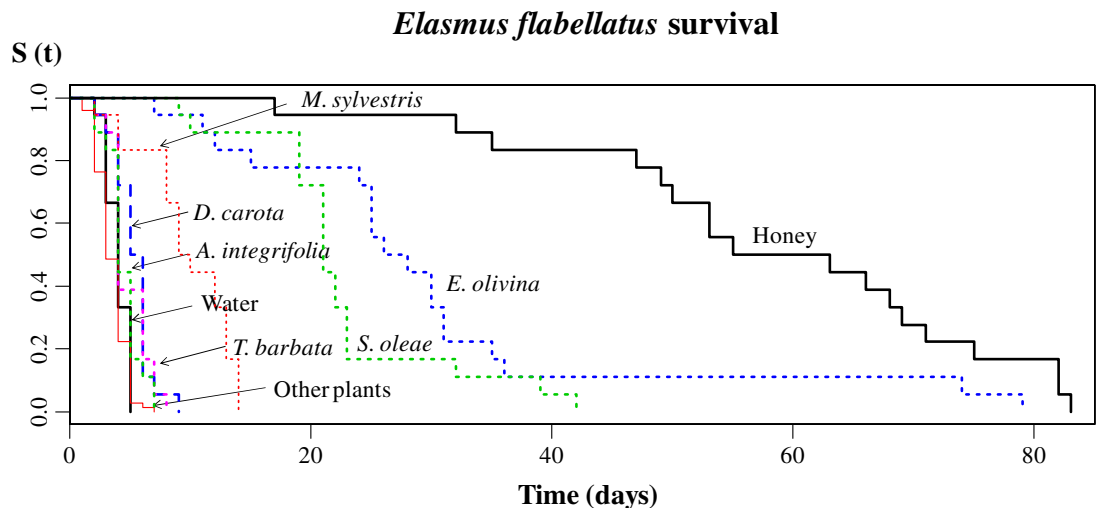

Fig. 2 Survival curves obtained by Kaplan-Meier estimates for adult females Elasmus flabellatus fed on different resources. The "other plants" curve correspond to A. arvensis, E. plantagineum, C. myconis, and $H$. perforatum treatments that were gathered in a survival curve to facilitate the reading of the graphic once the survival curves of these treatments were overlapped and not significantly different in the Cox's proportional hazard regression model (Cox PHM)

of sugary liquid food resources (Winkler et al. 2009). In this study, females fed on E. olivina reduced their risk of death by $60.60 \%$ when compared to females fed on S. oleae $(p=0.011)$. The viscosity of E. olivina honeydew, which forms bigger and thicker droplets, is visibly higher than that secreted by S. oleae (Villa, personal observation). The death hazards were significantly lower for females fed on E. olivina honeydew, although its viscosity is higher than that of $S$. oleae, which suggests that E. flabellatus can feed on viscous sugary liquids.

The highest survival of females fed on flowers was observed on M. sylvestris ( $9.78 \pm 0.87$ days) which reduced the risk of death when compared with all the flowers and only water $(>72.60 \%$ reduction, $p<0.001)$. Following $M$. sylvestris, the best performance was showed by females fed on D. carota $(5.28 \pm 0.37$ days $)$ and $T$. barbata $(4.83 \pm 0.37$ days), which reduced the risk of death when compared with all the other flowers and only water (D. carota, $>65.10 \%$ reduction, $p<0.003 ;$ T. barbata, $>54.90 \%$ reduction, $p=0.02$ ), with the exception of A. integrifolia ( $4.44 \pm 0.33$ days) that did not show significant differences with $D$. carota $(p=0.09)$ and T. barbata ( $p=0.368)$. Also, D. carota and T. barbata did not show significant differences among them $(p=0.445)$. A. integrifolia ( $3.06 \pm 0.29$ days) only reduced the risk of death when compared with $C$. myconis $(64.00 \%$ reduction, $p<0.001)$ and E. plantagineum $(49.10 \%$ reduction, $p=0.046$ ) (Fig. 3).

The relationship between floral architecture and the maximum width of E. flabellatus determines the accessibility to resources, in particular to nectar. The flower resources and the parasitoid used in this study are shown in Fig. 4.

The maximum width of $E$. flabellatus head and thorax was $0.496 \pm 0.013 \mathrm{~mm}$ and $0.519 \pm 0.014 \mathrm{~mm}$, respectively. These results are similar to those found by Nave et al. (2016) (head $=0.42 \pm 0.01 \mathrm{~mm}$; thorax $=0.53 \pm 0.02 \mathrm{~mm}$ ). The floral
Fig. 3 Lifespan (mean + SE) (days) for females of Elasmus flabellatus fed on different flower and insect honeydew food sources 
Fig. 4 Inflorescences of the plant species used in the experiments and Elasmus flabellatus females showing head and thorax widths. Sections of Asteroideae and Cichorioidae (Asteraceae) are shown
Flower resources and parasitoid

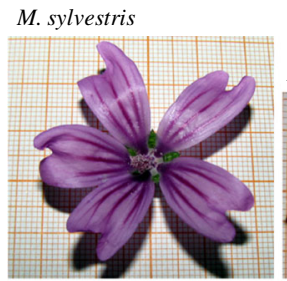

Asteroideae

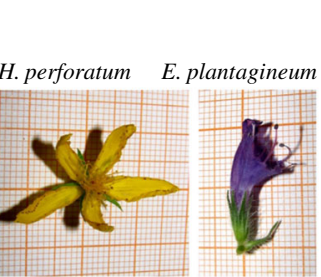

Cichorioideae

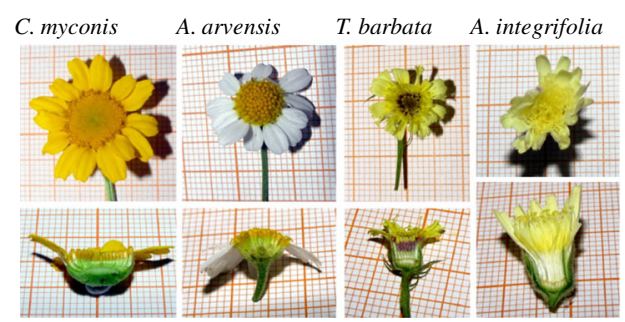

architecture can explain higher survivorships given by plants with open corollas and exposed nectaries, such as M. sylvestris and $D$. carota, as well as easily exploited resources, such as honeydews and honey, or the Cichorioideae T. barbata and A. integrifolia (Table 1). According to van Rijn and Wäckers (2016), the accessibility to nectar from Cichorioidae is likely limited by the close packing of the florets. The highest survival of E flabellatus on T. barbata in relation to A. integrifolia could also be related to its shorter corolla.

The death hazard for females fed on A. arvensis ( $3.83 \pm 0.19$ days), C. myconis (3.06 \pm 0.28 days), E. plantagineum $(3.33 \pm 0.35$ days $), H$. perforatum $(3.67 \pm 0.31)$, and only water ( $3.94 \pm 0.22$ days) did not show significant differences among them $(p>0.05)$. These plant treatments were gathered in a Cox PHM in order to obtain a unique survival curve (this procedure was adopted to facilitate the reading of the graphic once these curves were overlapped) (Fig. 2). In our work, survivorship given by the Asteroideae $A$. arvensis and C. myconis did not differ from water since the nectaries of these plants can be inaccessible for E. flabellatus because they are usually set at the base of the style in the disc floret (Sulborska and Weryszko-Chimielewska 2007) and the size of the parasitoid did not allow to reach them. The no effects on lifespan for E. plantagineum could be due to the long tube depth compared to the size of the parasitoid (Table 1, Fig. 4). In the case of $H$. perforatum, although it has a single and open flower, the no effect probably is due to the absence of nectaries (Stevens 2007).

In this study, dissections showed that none of the analyzed females consumed pollen and neither contained eggs. This suggests that $E$. flabellatus is synovigenic and requires additional food to produce eggs. The species Elasmus schimitti Ruschka showed to be provigenic (Gumovsky et al. 2007) and Elasmus nudus (Nees) was referred as synovigenic (Mehrnejad 2012). None of them performed host feeding. Studies of host feeding on P. oleae is currently not possible due to its complicated life cycle (three generations a year, each one feeding on different tissues of the olive tree), making it difficult to rear this moth and its parasitoids under laboratory conditions. However, Redolfi and Campos (2010) reared Elasmus steffani Viggiani, a P. oleae parasitoid, on the alternative host Ephestia kuehniella (Zeller) (Lepidoptera: Pyralidae) and observed host feeding. They found significant longer longevity for $E$. steffani females when fed on different

Table 1 Inflorescence type and mean $\pm \mathrm{SE}(\mathrm{mm})$ of inflorescence measurements of plant species tested in the experiment with Elasmus flabellatus

\begin{tabular}{|c|c|c|c|c|c|c|}
\hline Species & Type & Inflorescence diameter & Corolla diameter & Corolla length & Tube diameter & Tube width \\
\hline M. sylvestris & Single and open & - & $23.55 \pm 0.86$ & - & - & - \\
\hline H. perforatum & Single and open & - & $21.40 \pm 0.61$ & - & - & - \\
\hline E. plantagineum & Single tubular & - & - & - & $13.45 \pm 0.48$ & $1.77 \pm 0.06$ \\
\hline D. carota & Compound umbel & $44.85 \pm 2.27$ & $3.45 \pm 0.25$ & - & - & - \\
\hline C. myconis & Disc capitulum & $15.80 \pm 0.83$ & - & - & $2.92 \pm 0.08$ & $0.38 \pm 0.01$ \\
\hline A. arvensis & Disc capitulum & $15.20 \pm 0.61$ & - & - & $2.20 \pm 0.04$ & $0.46 \pm 0.01$ \\
\hline T. barbata & Ligulate capitulum & $15.30 \pm 0.69$ & - & $5.45 \pm 0.12$ & - & - \\
\hline A. integrifolia & Ligulate capitulum & $13.50 \pm 0.47$ & - & $7.74 \pm 0.29$ & - & - \\
\hline
\end{tabular}


food items in a descending order: honey solution $>$ honey solution plus host larvae $>$ without food. Similarly, for Tricogramma turkestanica Meyer (Hymenoptera: Trichogrammatidae), host feeding decreased its longevity, and this was attributed to the allocation of carbohydrates to egg production at the expenses of somatic maintenance (Ferracini et al. 2006). This could explain the lowest longevity of $E$. steffani with honey solution plus host larvae in Redolfi and Campos (2010) and provide an insight for E. fabellatus biology: probably E. flabellatus did not produce eggs because it needs to feed on the host, but this idea needs further research.

The selection of the most suitable food resources should be considered before implementing conservation biological control strategies. On the one hand, flower attractiveness and the accessibility of floral resources can influence E. flabellatus population dynamics in the field. Visual and olfactory attractiveness can determine the rate of visits to a given plant species or honeydew (Wäckers 2005 and reference therein), and these factors should be studied in future works. On the other hand, these food sources and floral cues may also benefit coinhabiting pests. Lavandero et al. (2006) found that some flowering plants enhanced the fitness of both the parasitoid and the herbivore. Balzan and Wäckers (2013) found that flowers differently influenced both pest and parasitoid lifetables. In our case, the studied food resources could also influence $P$. oleae population in the olive grove. Special attention should be given to $M$. sylvestris because its flowering peak coincides with the flight period of both E. flabellatus and P. oleae (Villa, personal observation). In addition, some attention should be given to $D$. carota; although its flowering peak is slightly later, it starts to bloom during the flight period of anthophagous generation of $P$. oleae (Villa, personal observation). Also, honeydews secreted by $S$. oleae and E. olivina occur simultaneously with $P$. oleae (Villa, personal observation). M. sylvestris and both honeydews improved survival and reproduction of $P$. oleae in laboratory experiments (Villa et al. 2016a). These food items should be tested in the field to assess the benefits for the parasitoid and for the pest. In the case of the hemipterans, it is also needed to evaluate the yield loss associated to these insects: although they usually are not responsible for substantial damages, they feed on the crop and constitute a risk. Despite these threats, this is the first time that potential food resources for E. flabellatus females were identified. In sustainable pest control, this novel knowledge can be an important starting point that will allow selecting food resources to be improved and investigated in the field.

\section{Conclusion}

In summary, in this study, several potential natural foods for E. flabellatus were identified in the olive grove agroecosystem. The best survival was accomplished with $S$. oleae and E. olivina honeydews, followed by M. sylvestris, D. carota, T. barbata, and A. integrifolia flowers. Thus, these food resources could be considered for conservation biological control. Our results also suggest that E. flabellatus is synovigenic and requires additional food resources for egg production. However, future investigation should be focused on studying the effect of these food resources on E. flabellatus and pest dynamics in the field, giving special attention to the relationships established between the secondary pests $S$. oleae and E. olivina and other elements of the agroecosystem, since they may result in a positive or negative effect in the final crop yield.

Acknowledgments The authors are grateful to the Portuguese Foundation of Science and Technology for financial support through the project EXCL/AGR-PRO/0591/2012 "Olive crop protection in sustainable production under global climatic changes: linking ecological infrastructures to ecosystem functions." M.V. thanks FCT, POPHQREN, and FSE for the PhD grant (SFRH/BD/70693/2010). This manuscript is part of M.V.'s $\mathrm{PhD}$ thesis.

\section{References}

Balzan MV, Wäckers FL (2013) Flowers to selectively enhance the fitness of a host-feeding parasitoid: adult feeding by Tuta absoluta and its parasitoid Necremnus artynes. Biol Control 67:21-31. doi:10. 1016/j.biocontrol.2013.06.006

Bento A, Torres L, Cabanas JE, Pereira JA (2007) A traça da oliveira, Prays oleae (Bernard). In: Torres L (ed) Manual de Protecção Integrada do Olival. UTAD, Vila Real, pp 202-229

Bollen KA, Jackman RW (1990) Regression diagnostics: an expository treatment of outliers and influential cases. In: Fox J, Long JS (eds) Modern methods of data analysis. Sage Publications, Newbury Park, pp 257-290

Byrne DN, Hendrix DL, Williams LH (2003) Presence of trehalulose and other oligosaccharides in hemipteran honeydew, particularly Aleyrodidae. Physiol Entomol 28:44-149. doi:10.1046/j.13653032.2003.00310.x

Cox DR, Oakes D (2001) Analysis of survival data. Chapman and Hall, London

Douglas AE (2006) Phloem-sap feeding by animals: problems and solutions. J Exp Bot 47(4):747-754

Ferracini C, Boivin G, Alma A (2006) Cost and benefits of host feeing in the parasitoid wasp Trichogramma turkestanica. Entomol Exp Appl 121:229-234. doi:10.1111/j.1570-7458.2006.00479.x

Flora-on (2015). URL http://www.flora-on.pt/. Accessed 3 Dec 2015

Fox J, Weisberg S (2011) Cox proportional-hazard regression for survival data in R. URL: www.socserv.mCaster.ca/jfox/Books/Companion/ appendix/Appendix-Cox-Regression.pdf. Accessed 10 October 2015

Gumovsky A, Rusina L, Firman L (2007) Bionomics and morphological and molecular characterization of Elasmus schimitti and Baryscapus elasmi (Hymanoptera: Chalcidoidea, Eulophidae), parasitoids associated with a paper wasp, Polistes dominulus (Vespoidea, Vespidae). Entomol Sci 10:21-34. doi:10.1111/j.1479-8298.2006.00195.x

Hendrix DL, Wei Y, Leggett JE (1992) Homopteran honeydew sugar composition is determined by both the insect and plant species. Comp Biochem Physiol B 101:23-27. doi:10.1016/0305-0491(92) 90153-I 
Jervis MA, Kidd NAC, Fitton MG, Huddleston T, Dawah HA (1993) Flower-visiting by hymenopteran parasitoids. J Nat Hist 27:67105. doi:10.1080/00222939300770051

Jervis MA, Ellers J, Harvey JA (2008) Resource acquisition, allocation, and utilization in parasitoid reproductive strategies. Annu Rev Entomol 53:361-385. doi:10.1146/annurev.ento.53.103106.093433

Lavandero B, Wratten SD, Didham RK, Gurr G (2006) Increasing floral diversity for selective enhancement of biological control agents: a double-edged sword? Basic Appl Ecol 7:236-243. doi:10.1016/j. baae.2005.09.004

Lundgren JG (2009) The pollen feeders. In: Relationship of natural enemies and nonprey foods. Springer Science \& Business Media, Dordrecht, pp 87-116

Mehrnejad MR (2012) Biological parameters of Elasmus nudus (Hymenoptera, Eulophidae), a parasitoid of the pistachio fruit hull borer moth, Arimania komaroffi (Lepidoptera, Pyralidae). Biocontrol Sci Techn 22:659-670. doi:10.1080/09583157.2012.677415

Nave A, Gonçalves F, Crespí AL, Campos M, Torres L (2016) Evaluation of native plant flower characteristics for conservation biological control of Prays oleae. B Entomol Res 106(2):249-257. doi:10. $1017 /$ S0007485315001091

Patt JM, Hamilton GC, Lashomb JH (1997) Foraging success of parasitoid wasps on flowers: interplay of insect morphology, floral architecture and searching behavior. Entomol Exp Appl 83:21-30. doi: 10.1046/j.1570-7458.1997.00153.x

Pereira JA (2004) Bioecologia da cochonilha negra, Saissetia oleae (Olivier), na oliveira, em Tras-os-Montes. PhD thesis, University of Tras-os-Montes e Alto Douro

R Core Team (2014) R: a language and environment for statistical computing. R Foundation for Statistical Computing, Vienna, Austria. URL http://www.R-project.org/. Accessed 3 December 2015

Redolfi I, Campos M (2010) Developmental and reproductive biology of the ectoparasitoid, Elasmus steffani, in a substitute host, Ephestia kuehniella. J Insect Sci 10:119. doi:10.1673/031.010.11901

Stevens PF (2007) Hypericaceae. In: Kubiztki (ed) The families and genera of vascular plants. Springer, Leipzig, pp 194-201

Sulborska A, Weryszko-Chimielewska E (2007) Anatomy and ultrastructure of floral nectar of Inula helenium L. (Asteraceae). Act Soc Bot Pol 76:201-207
Therneau T (2014) A package for survival analysis in S. R package version 2.37-7 URL http://CRAN.R-project.org/package=survival. Accessed 03 December 2015

Tzanakakis ME (2003) Seasonal development and dormancy of insects and mites feeding on olive: a review. Neth J Zool 52:87-224

van Rijn PCJ, Wäckers FL (2016) Nectar accessibility determines fitness, flower choice and abundance of hoverflies that provide natural pest control. J Appl Ecol 53:925-933

Villa M, Marrão R, Mexia A, Bento A, Pereira JA (2016a) Are wild flowers and insect honeydews potential food resources for adults of the olive moth, Prays oleae? J Pest Sci. doi:10.1007/s10340016-0745-8

Villa M, Santos SAP, Mexia A, Bento A, Pereira JA (2016b) Ground cover management affects parasitism of Prays oleae (Bernard). Biol Control 96:72-77. doi:10.1016/j.biocontrol.2016.01.012

Wäckers FL (2005) Suitability of (extra-) floral nectar, pollen, and honeydew as insect food sources. In: Wäckers FL, van Rijn PCJ, Bruin J (eds) Plant-provided food for carnivorous insects: a protective mutualism and its applications. Cambridge University Press, Cambridge, pp 17-74

Wäckers FL, van Rijn PCJ, Heimpel GE (2008) Honeydew as a food source for natural enemies: making the best of a bad meal? Biol Control 45:176-184. doi:10.1016/j.biocontrol.2008.01.007

Wade MR, Wratten SD (2007) Excised or intact inflorescences? Methodological effects on parasitoid wasp longevity. Biol Control 40:347-354. doi:10.1016/j.biocontrol.2006.08.015

Winkler K, Wäckers FL, Kaufman LV, Larraz V, van Lenteren JC (2009) Nectar exploitation by herbivores and their parasitoids is a function of flower species and relative humidity. Biol Control 50:299-306. doi:10.1016/j.biocontrol.2009.04.009

Yefremova ZA, Strakhova IS (2010) A review of the species of the genus Elasmus Westwood (Hymenoptera, Eulophidae) from Russia and neighboring countries. Entomol Rev 7:903-926. doi:10.1134/ S0013873810070080

Zhang G, Zimmermann O, Hassan SA (2004) Pollen as a source of food for egg parasitoids of the genus Trichogramma (Hymenoptera: Trichogrammatidae). Biocontrol Sci Techn 14:201-209. doi:10. 1080/09583150310001655648 